\title{
Dinâmica transnacional da mídia: processos de regulação na globalização comunicacional
}

Carlo José Napolitano e Augusto Junior da Silva Santos

\section{Resumo}

Este artigo visa identificar as normas jurídicas do Brasil que limitam a entrada de conteúdo midiático internacional no país e o investimento estrangeiro em veículos de comunicação nacionais. Na conjuntura da globalização, a mídia é marcada por sua dinâmica transnacional e pela formação de conglomerados globais que dominam a produção e a distribuição de bens simbólicos. Diante desse contexto, esta pesquisa exploratória evidencia que a legislação brasileira dispõe de normas que buscam assegurar espaços aos conteúdos locais, regionais e nacionais diante da expansão global, assimétrica e concentrada da indústria midiática. Apreende-se aqui que as políticas de comunicação pensadas apenas uma em dimensão nacional não contemplam adequadamente 0 cenário da globalização comunicacional.

\section{Palavras-Chave}

Mídia. Globalização. Pluralismo. Regulação.

Carlo José Napolitano I carlonapolitano@faac.unesp.br Doutor em Sociologia por meio do Programa de Pós-Graduação em Sociologia da Faculdade de Ciências e Letras de Araraquara da Universidade Estadual Paulista, Brasil. Professor do Departamento de Ciências Humanas e do Programa de Pós-Graduação em Comunicação da Universidade Estadual Paulista, Brasil.

\section{Augusto Junior da Silva Santos ।}

augustojr2005@hotmail.com Mestrando do Programa de Pós-Graduação em Comunicação da Universidade Estadual Paulista, Brasil. Bolsista pela Fundação de Amparo à Pesquisa do Estado de São Paulo - FAPESP (processo: 15/11783-1).

\section{Introdução}

Em tempos de globalização acentuada, transnacionalização dos meios de comunicação e rompimento de barreiras territoriais para o fluxo de informações, pode parecer paradoxal ou até mesmo inoperante a tentativa dos Estados-nações de tentarem, via legislação local, a regulamentação dos meios de comunicação e a proteção, por meio de reservas de mercado, dos conteúdos regionais e nacionais no intuito de preservar culturas locais, 0 pluralismo de meios e a diversidade de informação.

0 presente texto explora essas questões e indica que, embora as regulações jurídicas dos Estadosnações nesse contexto possam ser ineficazes, países como o Brasil buscam proteger as suas empresas de comunicação e os conteúdos nacionais das investidas do capital internacional.

Para cumprir esse roteiro, 0 trabalho está estruturado em quatro seções. Na primeira, traça um panorama da globalização econômica, aborda conceitos importantes para a compreensão da temática, como o de empresas multi e 
transnacionais, de internacionalização e aponta possíveis reflexos para as regulações jurídicas nacionais, em especial, para a dos países em desenvolvimento.

Na segunda seção, discute 0 histórico da globalização midiática e enfrenta a questão da concentração dos meios de comunicação em escala global, apresentando elementos atuais, como a comercialização de formatos de TV, e alguns dados sobre 0 tema. Na sequência, na terceira seção, analisa como a concentração midiática em plano global e a influência do poder econômico privado nesta atividade econômica podem impactar a liberdade de expressão e a pluralidade e diversidade de meios e conteúdos no fluxo internacional de informações.

Na quarta seção, apresenta os limites impostos pela legislação brasileira, constitucional e infraconstitucional, ao capital estrangeiro, bem como as tentativas locais de garantir pluralidade de conteúdos no mercado audiovisual e cinematográfico. Por fim, registra algumas considerações finais em sede de conclusão.

\section{Globalização econômica, transnacionalização empresarial e reflexos na regulação jurídica}

Globalização diz respeito às atividades que deixaram de ser exclusivamente regionais e passaram a compor a esfera mundial. Em sua instância organizacional, o termo se refere às atividades que podem ser administradas globalmente. Ele também condiz com a aparição de atividades recíprocas e interdependentes, as quais permitem a interação local-mundo (THOMPSON, 2008). Em outras palavras, a globalização é 0 estágio complexo da internacionalização, um fenômeno antigo e marcado pela ampliação geográfica das interações econômicas. Assim, globalização indica a integração - sob uma estratégia mundial, bem como sob a operação do mercado mundial - da produção, distribuição e consumo de bens e serviços (ORTIZ, 2007).

Embora se reconheça o mercantilismo como o seu berço, esse processo se deu, naquele período, em dimensões inferiores, se comparado aos cenários dos séculos XVII, XVIII e XIX (THOMPSON, 2008). Sobretudo, foi com o fim da Guerra Fria e, consequentemente, com a alteração de políticas econômicas dos países integrantes do bloco soviético que a internacionalização do capital foi intensificada (IANNI, 2007).

De acordo com Ianni (2007, p. 200), o capitalismo, desde a sua origem, se caracteriza como um sistema internacional. Segundo o autor, para Marx, "0 capitalismo é um processo civilizatório mundial" e que, apesar de se desenvolver em polos, estabelece bases interativas, agindo sobre as formas culturais e civilizatórias dos povos. Contudo, a ideia não é atestar que uma concepção de sociedade global já havia sido proposta por Marx. Na verdade: 
[...] trata-se apenas de reconhecer que algumas das instituições e interpretações desenvolvidas em seus escritos contemplam as dimensões mundiais do capitalismo, como o modo de produção e processo civilizatório. No pensamento de Marx e de alguns de seus continuadores podem encontrar-se recursos metodológicos e teóricos fundamentais para a inteligência da globalização (IANNI, 2007, p. 201).

A ascensão do neoliberalismo foi fundamental para intensificar esse contexto de interconexão mundial. Ademais, seus princípios de liberdade de comércio, estado-mínimo, divisão internacional do trabalho, mão invisível, etc. sintetizam a ordem econômica global, representada pelas empresas e produtos que transcendem fronteiras. Nessa perspectiva, compreende-se que o capitalismo global "é auto regulável, tende naturalmente a reequilibrar-se, vencer crises, distribuindo benefícios progressivamente a todos, em todos os cantos do mundo" (IANNI, 2008, p. 141).

Com 0 auxílio dos impulsos neoliberais, 0 fluxo econômico em escala global deu origem às chamadas multinacionais e transnacionais. 0 termo multinacional sinaliza que as empresas assim denominadas estão profundamente ancoradas nos diversos territórios anfitriões, abrangendo várias nacionalidades. Dessa forma, "a palavra multinacional neutraliza 0 caráter polêmico da expansão dessas novas unidades do capital supranacional transformando a economia mundial num mosaico de economias locais" (MATTELART, 2002, p. 101). Na última seção deste estudo, será visto que a legislação brasileira deu ênfase ao aspecto territorial quando da distinção entre empresa nacional e estrangeira, reforçando a ideia de empresas multinacionais.

Transnacional, por sua vez, designa uma gestão centralizada da organização, bem como a não coincidência territorial. Esse tipo de empresa se beneficia das condições naturais, financeiras, políticas e/ou jurídicas dos países hospedeiros, expondo tanto uma integração mundial quanto os conflitos de interesse entre tais instituições e os locais onde se instalam. Neste caso, 0 critério para definição da nacionalidade ou da transnacionalidade é 0 centro de controle, 0 centro de decisões que rompe com a questão territorial (MATTELART, 2002). Em consonância, Biernazki (2000, p.49) expõe que:

[...] A palavra transnacional enfatiza a distância, a não identificação pública com seus países de origem e até mesmo com os países nos quais eventualmente se localizam. Elas são cada vez mais vistas como empresas que trabalham para seus próprios fins, sem considerar outras instituições - muitas vezes, ignorando os melhores interesses de seus países, dos paises onde atuam, em busca de seus objetivos corporativos.

Essa caracterização das transnacionais reflete na ordem jurídica dos países. Segundo Faria (1997), as normas nacionais tradicionais de natureza binária (legal/ilegal, constitucional/ inconstitucional) não são suficientes para regular satisfatoriamente aspectos culturais, sociais, políticos e econômicos que, na esfera internacional, se tornam complexos. Além disso, 
os conglomerados transnacionais que se formam, considerando o seu poderio econômico, muitas vezes se sobrepõem à ordem jurídica dos Estados. Essas empresas exigem dos países hospedeiros privilégios fiscais e estruturais como condição para que se instalem em seu território, escolhendo, portanto, a quais normas nacionais se submeterão.

0 Estado-nação, em função da economia globalizada, tem sido obrigado a repensar "sua política legislativa, a reformular a estrutura de seu direito positivo e a redimensionar a jurisdição de suas instituições judiciais mediante amplas e ambiciosas estratégias de desregulamentação" (FARIA, 1997, p.47). As normas pertinentes à mídia não estão excluídas desse processo. Conforme a indústria midiática se transnacionaliza e se conglomera, a regulação da comunicação pensada unicamente em âmbito nacional deixa de corresponder às reais necessidades desse cenário.

Observe-se que 0 termo regulação tem sido empregado aqui no sentido de regulação normativa que compreende, segundo Aguillar (2006), a regulamentação legal e as atividades acessórias de fiscalização e imposição de sanções para as condutas ilícitas. Em outras palavras, regular é definir direitos e deveres, delimitar o exercício de direitos, clarificar as suas condições de uso, defender a sociedade e o indivíduo contra eventuais maus usos dos direitos, e esta ação, na contemporaneidade, está a cargo dos Estados que têm a função de compor os interesses individuais e sociais (GONÇALVES, 2003).
Nesses termos, a regulação jurídica pode ser medida através da análise da legislação, constitucional e legal, produzida pelo Congresso Nacional, que define e delimita direitos e prevê sanções para as condutas ilícitas, bem como pela interpretação e aplicação do direito pelo Judiciário, em especial pelo Supremo Tribunal Federal (STF), que, no limite, é o órgão responsável, em última instância, por explicitar as possibilidades de utilização de direitos previamente estabelecidos.

Para Grau (1991, p.49/50), a regulação das atividades, particularmente das econômicas, tem por finalidade preservar os mercados, o que "não seria possível sem uma legislação que o protegesse e uma racional intervenção, que assegurasse a sua existência", pois deixar 0 capitalismo à própria sorte do mercado é inviável. Ademais, a revolução tecnológica, na qual está inserida a comunicação midiática, resultou na exigência por parte das empresas atuantes no setor de um quadro legal claro e estável dessas relações jurídicas empresariais (GONÇALVES, 2003).

Como exemplo do reflexo da transnacionalização dos mercados na produção legislativa local, pode ser citada a Lei 9.610/98, que disciplina os direitos autorais e excepciona o princípio da territorialidade do direito pátrio ao prever que "os estrangeiros domiciliados no exterior gozarão da proteção assegurada nos acordos, convenções e tratados em vigor no Brasil". Essa lei protege formatos televisivos internacionais, como o Big Brother e o Masterchef. 
0corre, nesse contexto, um paradoxo entre a produção midiática transnacional, que prescinde da ideia da territorialidade, e a legislação local, pautada por esse quesito. A despeito desse paradoxo, algumas esferas legislativas têm cunho internacionalista, como é o caso específico dos direitos autorais. Estes estão intimamente ligados às produções de caráter transnacional, como os formatos mencionados. Trata-se de produtos midiáticos decorrentes da expansão global da comunicação e inseridos na esfera da concentração midiática, como será visto na próxima seção.

\section{Expansão global da comunicação e concentração midiática}

0 princípio da expansão global da comunicação está ligado à criação de redes comunicacionais em escala mundial, as quais foram arquitetadas a partir do século XIX.

Motivações econômicas, políticas e militares impulsionaram o desenvolvimento dessas redes e, concomitantemente, firmavam a existência de um mundo em globalização. A fim de estruturar 0 desenvolvimento global da comunicação, Thompson (2008) apresenta-o dividido em três etapas.

A primeira compreende a criação do telégrafo, meio que, satisfatoriamente, fez uso do potencial comunicativo da eletricidade. As redes de cabos submarinos representam o primeiro sistema global de comunicação que possibilitou a conexão em tempo quase real entre os grandes centros urbanos europeus e norte-americanos. Em 1870, foram registradas cerca de 30 milhões de transmissões telegráficas e, na transição para 0 século seguinte, 0 meio foi responsável por modificar a importância "econômica da informação, os métodos de coleta, tratamento e codificação" (MATTELART, 2002, p. 26).

A segunda etapa apresentada pelo autor refere-se à ascensão de agências internacionais de notícias e à divisão do mundo em função de suas operações exclusivas. As três grandes e únicas agências internacionais existentes naquele período eram a francesa Havas, atual Agence FrancePresse (AFP), fundada em 1835; a alemã Wolff, criada em 1849 e extinta em 1934; e a britânica Reuters, fundada em 1851. 0 trio, por meio de acordos, delimitou seus territórios de atuação e estabeleceu laços com as "elites políticas e comerciais das nações que lhes serviam de sede, desfrutando certo grau de patronato político e fornecendo informações que eram valiosas para a administração do comércio e da diplomacia" (THOMPSON, 2008, p. 140). A hegemonia mundial do cartel só se desfez após a $1^{\mathrm{a}}$ Guerra Mundial, quando surgiram as agências norte-americanas Associated Press (AP) e United Press Association (UPA), atual United Press International (UPI). No cenário pós-2 $2^{\mathrm{a}}$ Guerra, estabeleceram-se como as quatro maiores agências a Reuters, a AP, a UPI e a AFP (THOMPSON, 2008).

A exploração do espaço eletromagnético por organizações internacionais representa a terceira 
etapa da globalização da comunicação. Embora tenha havido experiências de transmissões radiofônicas ao exterior anteriormente, foi a partir dos primeiros satélites, na década de 1960, que a radiodifusão teve sua abrangência internacional potencializada (THOMPSON, 2008). Se, a princípio, as experiências de transmissão para além das fronteiras foram protagonizadas pela exploração estatal, posteriormente foi a iniciativa privada do capital internacional que passou a dominar esse setor.

Essas três etapas e a ascensão de uma nova ordem econômico-cultural deram sustentação aos investimentos dos quais a comunicação passou a ser alvo. Assim, geraram-se "fusões e toda sorte de alianças corporativas, devido à possibilidade aberta para 0 incremento dos negócios e à midiatização da sociedade atual, o que concede centralidade à mídia" (BRITTOS, 2005, p . 134). Nessa conjuntura, empresas produtoras e distribuidoras de conteúdos e formatos em uma lógica transnacional se estruturaram e se fortaleceram, ampliando, por exemplo, a abrangência de emissoras e a comercialização cross-borders de bens simbólicos.

Acompanhando a tendência, os grupos de mídia do Brasil também se inseriram na dinâmica transnacional da mídia. Ao mesmo tempo em que o país é forte consumidor de conteúdos (filmes, séries) e formatos estrangeiros, oriundos principalmente dos EUA, as telenovelas, sobretudo as da Rede Globo, são as mais maiores representantes brasileiras no fluxo internacional de bens midiáticos. Quanto ao âmbito de cobertura das emissoras, verifica-se a presença no exterior de dois canais brasileiros da rede aberta: a TV Globo Internacional e a Record Internacional. Há ainda, desde 2010, o canal da Empresa Brasil de Comunicação (EBC), a TV Brasil Internacional. Este, todavia, está inserido em outra lógica de operaçãa ${ }^{1}$.

A presença de grupos e produções latinas na esfera global da comunicação é, no entanto, sutil em relação à primazia dos EUA. Esse fato sinaliza 0 ambiente assimétrico da dinâmica transnacional da mídia, no qual "as corporações mediáticas mundializadas reestruturam o processo de produção e distribuição do espetáculo de modo a integrar, numa mesma cadeia produtiva, seus elos de produção, programação e distribuição" (DANTAS, 2013, p. 109). Ao mesmo tempo, essa cadeia é dominada por conglomerados midiáticos originados de um sucessivo processo de fusões e incorporações entre empresas. É 0 caso das estadunidenses Time Inc. e Warner Bros que, em 1986, fundiram-se, concentrando, respectivamente, os principais grupos de imprensa e de produção cinematográfica sob uma mesma ordem empresarial. 
A fim de ilustrar esse cenário, apresentamse aqui dados da lista divulgada, em 2012, pelo Instituto para Políticas de Mídia e Comunicação (IMF), da Alemanha, com os 50 maiores conglomerados de comunicação do mundo. Dos dez primeiros, apenas três não são estadunidenses. São esses respectivamente: Comcast/NBC/Universal (EUA); The Walt Disney Company (EUA); Google Inc. (EUA); News Corp. Ltd. (EUA); Viacom Inc./CBS Corp. (EUA); Time Warner Inc. (EUA); Sony Entertainment (Japão); Bertelsmann AG (Alemanha); Vivendi S.A. (França); e Cox Enterprises Inc. (EUA). 0 faturamento anual desses grupos varia de 11 bilhões a 40 bilhões de euros. A primeira latino-americana a aparecer na lista é a brasileira Rede Globo, em $25^{\circ}$ lugar, com uma receita anual de aproximadamente 4 bilhões de euros (DANTAS, 2013).

$\mathrm{Na}$ atual conjuntura da expansão global da comunicação, deve-se ainda destacar a comercialização de formatos televisivos, mercado que teve início na década de 1950, quando alguns game shows criados nos Estados Unidos começaram a ser vendidos para outros países. Nas décadas de 1990 e 2000, o fluxo mundial de formatos de TV se ampliou e se tornou uma indústria multibilionária. Esse modelo de negócio caracteriza um genuíno espaço transnacional, ao passo que integra redes comerciais, agentes econômicos, organizações e mercadorias através das fronteiras (CHALABY, 2015). Nesse contexto, muitos conglomerados midiáticos, inclusive os citados aqui, têm investido nesse segmento.

Em relação ao fluxo de comercialização dos formatos, por um lado, o eixo da exportação é concentrado e dominado pelos Estados Unidos e pelo Reino Unido. Por outro lado, o eixo da importação $0^{2}$ é diversificado, com destaque para a América Latina, onde nota-se que "emissoras brasileiras têm se tornado consumidoras ávidas de formatos" (CHALABY, 2015, p. 11, tradução nossa). Esse fato pode ser verificado pelo sucesso que programas como Masterchef, Big Brother, The Voice e outros têm feito no país.

Deve-se pontuar que a comunicação também tem se expandido globalmente com base nas "novas" plataformas. Por meio da internet, as transmissões via streaming, os serviços on demand e a utilização de redes sociais, como o YouTube, delineiam o cenário contemporâneo e complexo do setor. Trata-se de uma cadeia que engloba, de um lado, novos hábitos de consumo e, do outro, um novo nicho mercadológico da comunicação, no qual grupos de mídia são obrigados a inovar enquanto novas empresas e segmentos emergem, como é o caso da Netflix. 
Em complemento ao apresentado nesta seção, o atual panorama da comunicação global pode ser sintetizado a partir do seguinte diagnóstico:

(1) La propiedad de los medios está cada vez más concentrada. (2) Al mismo tiempo, los conglomerados mediáticos ahora pueden ofrecer diversos productos en una plataforma, así como un solo producto en distintas plataformas. También forman nuevos productos combinando partes digitales de otros productos. (3) La segmentación de las audiencias, adaptando se a ellas, para maximizar los ingresos por publicidad se fomenta mediante el movimiento de productos de comunicación entre plataformas. (4) Por último, el éxito de estas estrategias viene determinado por la capacidad de las redes internas de medios para encontrar economías de sinergia óptimas que aprovechen el entorno cambiante de las comunicaciones (CASTELLS, 2009, p. 112).

Esses fatores em adição ao que foi exposto e articulado nesta seção norteiam, como será abordado a seguir, a reflexão sobre a interferência regulatória nos fluxos transnacionais da mídia, no sentido de garantir a manutenção e 0 incentivo à diversidade de conteúdos e de representações sob lógicas múltiplas e não concentradas. Portanto, à medida que os lucros se centralizam no contexto da comunicação midiática, 0 domínio sobre 0 capital simbólico também se torna restrito.

\section{Pluralismo, liberdade de expressão e regulação}

A desterritorialização do segmento midiático se estabeleceu no mercado global, como sinalizado, de forma assimétrica e concentrada. Esses dois aspectos interferem na diversidade de conteúdo e de representações em circulação mundialmente, fato que prejudica a construção de uma dinâmica transnacional da mídia pautada pelo pluralismo. 0 cumprimento desse princípio é uma obrigação social dos meios de comunicação e responsável por fomentar diálogos sociais entre "a mídia e os cidadãos, entre a administração privada de um bem público - como é o caso da informação - e as responsabilidades públicas decorrentes dessa concessão da sociedade" (REY, 2002, p. 97).

0 pluralismo é um estado conquistado por meio da existência de múltiplos veículos de comunicação capazes de produzir e distribuir bens simbólicos, tendo a diversidade como engrenagem. Portanto, uma esfera midiática plural é construída a partir da interconexão de fatores que vão desde a estrutura organizacional dos meios até 0 momento de distribuição das produções simbólicas.

A constituição de um ambiente comunicacional plural é um dos pilares que garante a liberdade de expressão, direito fundamental e associado a todos os outros que lhe são conexos. Porém, não se trata de um direito absoluto. Ademais, assegurar a livre manifestação de opiniões, pensamentos e ideias pode ser uma tarefa conflituosa, pois esse direito deve ser direcionado tanto a "quem fala/ escreve/atua quanto a quem ouve/lê/vê - no caso deste, 0 direito de acesso à informação e às ideias" (MENDEL; SALOMON, 2011).

As abordagens regulatórias são pensadas tendo como parâmetro os efeitos sobre a liberdade 
de expressão. Um dos enfoques sobre 0 tema defende a desregulamentação total dos meios, sem qualquer imposição às empresas de mídia por parte do Estado. Para outro enfoque, deve-se instaurar normas a fim de restringir a atividade midiática e promover políticas socioculturais de comunicação (REY, 2002). Nos EUA, por exemplo, essa dicotomia está presente na interpretação da Primeira Emenda, norma constitucional que garante a liberdade de expressão no país. De um lado, há a concepção libertária sobre 0 dispositivo, a qual entende que não deve haver interferências ou limitações a quem se expressa, como jornalistas, escritores, compositores, etc. De outro, há a leitura democrática da Emenda, ou seja, compreende-se que 0 Estado deve regular 0 "mercado de ideias", a fim de proteger os interesses coletivos (BINENBOJM, 2006).

A partir desses enfoques divergentes, verificamse, primeiramente, ideias liberais, as quais têm o livre mercado como princípio para assegurar a liberdade de expressão. 0 Estado, instância de amplo poder, é visto como fonte potencial de restrição à livre exposição e circulação de opiniões e informações, sendo uma ameaça à imprensa e à mídia, como no caso de regimes autoritários. Nesse sentido, tal direito só seria garantido se "as instituições da imprensa fossem independentes do estado e situadas no domínio privado onde poderiam se desenvolver com um mínimo de constrangimento"

(THOMPSON, 2008, p. 208).
Em segundo lugar, nota-se a partir da atual configuração dos grupos midiáticos que a falta de regulação reflete no crescimento desenfreado dessas empresas. Não o poder do Estado, mas os poderes de poucas organizações passaram a reger as produções midiáticas de maneira que "não contribuem para o pluralismo, desnaturalizam a natureza pública da comunicação, concentram as oportunidades e tudo passa a ser simplesmente negócio" (REY, 2002, p. 98).

[...] A visão não intervencionista da atividade econômica não é necessariamente 0 melhor fiador da liberdade de expressão, pois um mercado desregulado pode se desenvolver de modo a reduzir efetivamente a diversidade e a limitar a capacidade de muitos indivíduos de se fazerem ouvir. [...] 0 mercado sozinho não cultiva necessariamente a diversidade e o pluralismo na esfera da comunicação. Como em outros campos produtivos, as indústrias da mídia são orientadas principalmente pela lógica do lucro e da acumulação de capital, e não há correlação necessária entre a lógica do lucro e o cultivo da diversidade (THOMPSON, 2008, p. 208-209).

No intuito de encontrar medidas para que nem o Estado e nem a iniciativa privada totalmente autônoma dominem as práticas comunicacionais, Thompson (2008) defende a implementação do pluralismo regulado, uma estrutura institucional que vai além dos interesses comerciais dos grupos de mídia. Essa regulação parte do princípio de que a pluralidade seja um imperativo sobre a concentração de poderes, sejam simbólicos ou econômicos. Para tanto, é necessário fixar uma legislaçã $0^{3}$ que limite tanto a formação de conglomerados midiáticos quanto "uma 
legislação que crie condições favoráveis para 0 desenvolvimento de organizações da mídia que não façam parte dos grandes conglomerados já existentes" (THOMPSON, 2008, p. 210). Portanto, caberia ao viés legislativo fomentar também 0 desenvolvimento de novas produtoras, as quais equilibrariam a oferta e 0 tipo de conteúdo em fluxo na esfera global. Contudo, o princípio do pluralismo regulado não fornece diretrizes específicas sobre as maneiras mais adequadas de controle, propriedade e organização das indústrias midiáticas.

Tratar sobre pluralismo ou, em outras palavras, sobre a garantia da liberdade de expressão na dinâmica transnacional da mídia requer análises que transcendam os espaços nacionais. Conforme a abrangência territorial dos mercados midiáticos se expande, políticas domésticas de comunicação deixam de atender a:

um mundo onde as fronteiras nacionais são continuamente devassadas pelo fluxo de bens simbólicos. Hoje não é mais possível pensar na dimensão da comunicação como suplementar à política nacional de regulamentação da mídia; pelo contrário, a dimensão internacional deve estar no centro de qualquer reflexão nacional sobre uma política de comunicação viável e coerente (THOMPSON, 2008, p. 211).
Durante as décadas de 1970 e 1980, houve iniciativas que tiveram como fim regular internacionalmente a concentração e as atividades midiáticas. A UNESCO promoveu debates sobre os prejuízos no fluxo internacional de informação e de comunicação provocados, principalmente, pela concentração informacional em decorrência da existência do cartel das agências de notícias. Naquele período, conferências e comissões sobre a "Nova Ordem Mundial da Informação e Comunicação" (NWIC0) foram organizadas. Buscavam-se o equilíbrio e a democratização no trânsito internacional de conteúdos informativos.

Em 1980, o órgão publicou o relatório MacBride, documento pioneiro de ordem multilateral que identificava "a existência de um grave desequilíbrio no fluxo mundial de informação, apresentava possíveis estratégias para reverter a situação e reconhecia o direito à comunicação" (LIMA, 2011, p. 241). 0 relatório foi "0 mais completo relato já produzido sobre a importância da comunicação na contemporaneidade" (RAMOS, 2005, p. 246).

0 documento, no entanto, sofreu forte oposição dos conglomerados midiáticos globais e dos Estados Unidos e do Reino Unido, os quais, como forma de protesto, se desligaram da UNESCO. Apesar dos dispõe também que as outorgas e renovações de concessões, permissões e autorizações dos serviços de radiodifusão devam observar o princípio da complementaridade dos serviços privado, público e estatal, com a intenção clara de promover a pluralidade dos meios de comunicação (art. 223), além de prever regras acerca da pluralidade de conteúdo nos meios de comunicação (art. 221), como será visto na última seção. 
impasses, os debates resultaram em formas alternativas de comunicação, principalmente nos chamados países de Terceiro Mundo, além de ter fortalecido a consciência sobre as desigualdades relacionadas à globalização da comunicação (THOMPSON, 2008).

As inquietações acerca dessa conjuntura resultaram na realização de cúpulas internacionais para discutir sobre a ordem mundial da mídia na contemporaneidade. Além disso, constata-se que alguns países estabeleceram sua própria legislação de caráter "protecionista". Instituíram uma cota para conteúdos estrangeiros em programações televisivas e nos cinemas; criaram leis sobre 0 investimento estrangeiro em veículos midiáticos nacionais e demais normas que buscam garantir a pluralidade e a complementaridade dos meios de comunicação no ambiente da globalização.

No contexto brasileiro, verifica-se a existência de normas que visam garantir o protagonismo nacional no setor midiático, tanto na dimensão do conteúdo quanto no sentido empresarial.

Entretanto, diante da atual dinâmica transnacional da mídia - incluindo a expansão da internet, dos serviços on demand, via streaming e da comercialização de formatos de TV -, a legislação brasileira conta, de fato, com suportes para preservar as produções, produtoras e veículos nacionais? Busca-se na próxima seção apresentar direcionamentos a fim de esclarecer essa questão.

\section{Limites jurídicos brasileiros para a expansão internacional da mídia}

Considera-se para fins deste trabalho que a Constituição de 1988, elaborada exatamente no período anterior ao fim da Guerra Fria e ruína do bloco soviético, marco fundamental para a internacionalização do capital (IANNI, 2007), em sua redação original, por esta questão cronológica, podia ser compreendida como nacionalista e avessa ao capital estrangeiro.

Algumas regras nacionalistas, contudo, foram retiradas do texto constitucional, através de Emendas Constitucionais, especialmente no primeiro ano do primeiro mandato do governo Fernando Henrique Cardoso. Essas Emendas tinham por escopo abrir o mercado brasileiro ao capital e ao empreendedor estrangeiro. Tais medidas também objetivaram reafirmar a opção pelo modelo econômico liberal, que não tolera reserva de mercado, protecionismo, atuação do Estado na seara econômica e concessão de privilégios. 0 campo da comunicação social não ficou longe dessas formas de regulação.

\section{A Constituição Federal no caput do artigo 222,} Título VIII, Capítulo V que trata da comunicação social, em sua redação original, previa que a propriedade de empresa jornalística e de radiodifusão sonora e de sons e imagens seria privativa de brasileiros natos ou naturalizados há mais de dez anos, cabendo a estes a função de administrá-las e orientá-las intelectualmente. 
$0 \S 1^{0}$ vedava a participação de pessoa jurídica no capital social dessas empresas, com exceção da participação de partido político e de sociedades cujo capital pertencesse exclusiva e nominalmente a brasileiros natos ou naturalizados. $0 \S 2^{\circ}$ determinava que essa participação somente poderia ocorrer através de capital sem direito a voto e não poderia exceder a trinta por cento do capital social.

Esse artigo, porém, foi alterado pela Emenda Constitucional de $n^{0} 36$, de 28.05.02. Por essa emenda, 0 artigo 222 passou a prever que a propriedade de empresa jornalística e de radiodifusão sonora e de sons e imagens é privativa de brasileiros natos ou naturalizados há mais de dez anos, ou de pessoas jurídicas constituídas sob as leis brasileiras e com sede no país. $0 \S 1^{0}$ estipula que, em qualquer dos casos disciplinados no caput, pelo menos $70 \%$ do capital total e do capital votante dessas empresas deverá pertencer, direta ou indiretamente, a brasileiros natos ou naturalizados há mais de dez anos, que exercerão obrigatoriamente a gestão das atividades e estabelecerão o conteúdo da programação. Pelo $\S 2^{\circ}$, a responsabilidade editorial e as atividades de seleção e direção da programação veiculada são privativas de brasileiros natos ou naturalizados há mais de dez anos, em qualquer meio de comunicação social. $0 \S 3^{\circ}$ dispõe que os meios de comunicação social eletrônica, independentemente da tecnologia utilizada para a prestação do serviço, deverão garantir prioridade aos profissionais brasileiros natos ou naturalizados na execução de produções nacionais. $0 \S 4^{0}$ remete à lei a disciplina da participação de capital estrangeiro nessas empresas conforme preceitua 0 $\S 1^{0}$ supramencionado. Pelo $\S 5^{0}$, as alterações de controle societário das empresas tratadas pelo $§ 1^{0}$ deverão ser comunicadas ao Congresso Nacional.

Desta forma, a Emenda $n^{0} 36$ permite que empresa com sede no Brasil e constituída conforme as leis brasileiras possa ser proprietária desse tipo de sociedade. Aqui está a regra de territorialidade, a qual define a nacionalidade das empresas, independentemente da origem do capital. Entretanto, mantém a nova redação algumas restrições ao investimento estrangeiro, tais como $0 \S 1^{0} \mathrm{e} 0 \S 3^{\circ}$. Este último parágrafo inova a ordem jurídica constitucional ao fazer reserva de mercado aos profissionais brasileiros.

As justificativas para a existência de regras restritivas ao capital estrangeiro são de que elas visavam "proteger o país contra a influência estrangeira em certos setores" (CAVALCANTI, 1949 , p. 69) e objetivavam garantir que os meios de comunicação não fossem manipulados por interesses de países estrangeiros (BASTOS; MARTINS, 1990, p. 855).

Ainda na Constituição Federal, outras duas regras podem ser consideradas como limitantes ao capital ou à influência estrangeira. Trata-se dos incisos II e III do artigo 221 que obrigam a 
produção e a programação das emissoras de rádio e televisão a cumprirem os seguintes princípios: I - promoção da cultura nacional e regional e estímulo à produção independente que objetive a sua regulação; II - regionalização da produção cultural, artística e jornalística, conforme percentuais estabelecidos em lei. Fica evidente aqui a intenção de preservar a identidade e a cultura nacionais, diversificando os conteúdos informacionais.

Em termos de legislação infraconstitucional, conforme já mencionado, a Lei $\mathrm{n}^{0} 12.485 / 11$, no intuito de regulamentar os incisos do artigo 221 da Constituição, estabelece inúmeras regras protetivas ao capital e à produção de conteúdo nacional, dentre elas podem ser citadas as contidas no artigo $3^{\circ}$, incisos II, III e IV que estipulam ser princípios fundamentais da comunicação audiovisual de acesso condicionado, respectivamente, a promoção da diversidade cultural e das fontes de informação, produção e programação, a promoção da língua portuguesa e da cultura brasileira e o estímulo à produção independente e regional.

Por sua vez, o capítulo IV da lei estipula regras protetivas às produções de conteúdo nacional. Essas regras estão especialmente elencadas no artigo 16 da lei, o qual dispõe que nos canais de espaço qualificado - aqueles que no horário nobre veiculem majoritariamente conteúdos audiovisuais, considerados estes o espaço total do canal de programação, excluindo-se conteúdos religiosos ou políticos, manifestações e eventos esportivos, concursos, publicidade, televendas, infomerciais, jogos eletrônicos, propaganda política obrigatória, conteúdo audiovisual veiculado em horário eleitoral gratuito, conteúdos jornalísticos e programas de auditório ancorados por apresentador - um mínimo de 3h30 (três horas e trinta minutos) semanais dos conteúdos veiculados deverá ser brasileiro e que metade dessas produções deverá ter sido produzida por produtoras brasileiras independentes.

A lei também inova 0 sistema jurídico brasileiro criando uma nova modalidade de restrição ao capital estrangeiro. Trata-se da definição de produtora brasileira, prevista no artigo $2^{\circ}$, inciso XVIII, nos seguintes termos: empresa que produza conteúdo audiovisual que atenda às seguintes condições, cumulativamente: a) ser constituída sob as leis brasileiras; b) ter sede e administração no país; c) 70\% do capital total e votante devem ser de titularidade, direta ou indireta, de brasileiros natos ou naturalizados há mais de dez anos; d) a gestão das atividades da empresa e a responsabilidade editorial sobre os conteúdos produzidos devem ser privativas de brasileiros natos ou naturalizados há mais de dez anos. Aparentemente, esta regra contraria 0 texto constitucional, pois cria restrição ao capital estrangeiro não previsto na nossa lei maior. No entanto, o STF não visualizou ofensa à ordem constitucional, declarando a lei constitucional na Ação Declaratória de Inconstitucionalidade ${ }^{0}$ 4679, proposta pelo Partido Democratas. 
Uma outra inovação da 12.485/11, e que aqui se defende, é a possibilidade de essas regras serem aplicadas a qualquer tipo de serviço de oferta de conteúdos midiáticos, incluindo-se os serviços on demand, à exceção dos serviços de radiodifusão. De acordo com 0 artigo $1^{0}$, Parágrafo Único, "excluem-se do campo de aplicação desta Lei os serviços de radiodifusão sonora e de sons e imagens". Por sua vez, 0 artigo $2^{\circ}$, inciso VI considera como Comunicação Audiovisual de Acesso Condicionado o complexo de atividades que permite a emissão, transmissão e recepção, por meios eletrônicos quaisquer, de imagens, acompanhadas ou não de sons, que resulta na entrega de conteúdo audiovisual exclusivamente a assinantes. 0 inciso I do mesmo artigo dispõe que assinante é o contratante do serviço de acesso condicionado.

Diante disso e por analogia ${ }^{4}$, compreende-se aqui que as atividades da Netflix e do YouTube no Brasil estão submetidas à Lei 12.485. Ambos podem ser enquadrados como serviço de comunicação audiovisual de acesso condicionado, haja vista a amplitude da expressão "por meios eletrônicos quaisquer", contida no inciso VI, do artigo $2^{\circ}$, que os abarcaria. Ademais, vislumbrase a possibilidade de os usuários desses serviços serem considerados assinantes, conforme inciso I do mesmo artigo, pois eles contratam serviços condicionados a um pagamento, seja de acesso ao provedor de conteúdo propriamente dito (Netflix) ou para 0 acesso à internet (YouTube e Netflix).

Por fim, também pode ser considerada como uma limitação à entrada de produtos midiáticos estrangeiros no Brasil a reserva de mercado para a exibição de filmes brasileiros em salas de exibição, regra que ficou conhecida como Cota de Tela. Essa regra foi criada pela Medida Provisória 2.228-1/2001, a qual dispõe em seu artigo 55 que, por um prazo de 20 anos, contados a partir de 5 de setembro de 2001, as empresas proprietárias, locatárias ou arrendatárias de salas, espaços ou locais de exibição pública comercial deverão exibir obras cinematográficas brasileiras de longa-metragem, por um número de dias fixado, anualmente, por decreto, ouvidas as entidades representativas dos produtores, distribuidores e exibidores. 0 decreto 8.386/14 estipula a Cota de Tela para 0 ano de 2015. Essa lei foi alvo de questionamento quanto à sua constitucionalidade, estando, atualmente, pendente de apreciação de Recurso Extraordinário 627432, impetrado pelo Sindicato das Empresas Exibidoras Cinematográficas do Estado do Rio Grande do Sul, junto ao STF.

Verifica-se, por esses exemplos aqui apontados, que a legislação brasileira, muito embora tenha estabelecido, na década de 1990, a abertura ao capital internacional, essa receptividade encontra limites, como de participação em apenas $30 \%$ do 
capital votante nas empresas de comunicação e as reservas de mercado, estabelecidas para 0 serviço de audiovisual e cinematográfico, que encontram também respaldo no citado artigo 221 da Constituição.

\section{Considerações finais}

As inovações tecnológicas e a internacionalização do capital impulsionaram novas e eficientes formas de comunicação capazes de interconectar todo, ou quase todo, o mundo. Assim, alcançar audiências distantes tornou-se uma realidade para os meios de comunicação, os quais integram e fortalecem o processo de globalização.

A assimetria que marca a dinâmica transnacional da mídia evidencia a hegemonia de determinados grupos sobre o fluxo internacional de bens simbólicos. As referências midiáticas mundiais passam a ser restritas à lógica dos conglomerados que dominam todo o processo de produção e distribuição de conteúdos informativos e de entretenimento.

Esse panorama revela os prejuízos à complementaridade dos meios, ao pluralismo em âmbito mundial, bem como indica a presença da face excludente e desigual da globalização no setor da comunicação.

Apreende-se aqui a importância da existência, de fato, de ampla regulação legal nacional no sentido de garantir, ou pelo menos tentar, a pluralidade de conteúdos, tendo em vista produções locais e regionais, bem como assegurar que 0 capital internacional não se sobreponha aos interesses nacionais, mesmo que essas tentativas estabelecidas na legislação pátria possam ser consideradas ineficazes. Essas proteções legais visam, portanto, a um ambiente midiático brasileiro plural e protegido em relação ao poder econômico do capital transnacional, pelo menos no aspecto formal da regulação jurídica.

No entanto, a despeito disso, verifica-se no plano da realidade dos fatos que determinados programas produzidos local, regional e nacionalmente, os quais, sob o aspecto legal, são considerados produções nacionais, na verdade apenas reproduzem formatos transnacionais, mantendo-se a identidade dos mesmos nas produções locais. Nesse sentido, pouco contribuem, considerando-se um planejamento estratégico, para a proteção de valores culturais nacionais, regionais e locais, tal como preconizado pela legislação, muito embora elementos da cultura local neles sejam incorporados, ocorrendo, deste modo, um hibridismo entre aspectos nacionais e globais.

Por fim, cabe aos debates e reflexões sobre a regulação transcenderem, assim como a comunicação midiática, os limites fronteiriços para que prevaleçam políticas coerentes ao cenário complexo e contemporâneo do setor. 


\section{Referências}

AGUILLAR, Fernando Herren. Direito econômico.

São Paulo: Atlas, 2006.

BASTOS, Celso Ribeiro; MARTINS, Ives Gandra.

Comentários à Constituição do Brasil. São Paulo:

Saraiva, 1990.

BIERNAZKI, Willians. Globalização da comunicação.

Revista Comunicação e Educação. São Paulo, Ano

VII, $n^{0} 19, p .46-65,2000$.

BINENBOJM, Gustavo. Meios de comunicação de massa, pluralismo e democracia deliberativa. As liberdades de expressão e de imprensa nos EUA e no Brasil. Redae, $n^{0} 5$, fev/abril 2006.

BRITTOS, Valério. Globo, transnacionalização e capitalismo. In: BRITTOS, Valério; BOLAÑO, César R. S. (Org.). Rede Globo: 40 anos de poder e hegemonia. São Paulo: Paulus, 2005. p. 131-145.

CASTELLS, Manuel. Comunicacion y poder. Madrid: Alianza, 2009.

CAVALCANTI, Themístocles Brandão. A Constituição

federal comentada. Rio de Janeiro: José Konfino

Editor, 1949, v. IV.

CHALABY, Jean. The advent of the transnational TV format tranding system: a global commody chain analysis. Media, Culture \& Society. vol. 1, n. 19, p. 1-19, 2015.

DANTAS, Marcos. Comunicações, desenvolvimento, democracia: desafios brasileiros no cenário da mundialização mediática. São Paulo: Editora Fundação Perseu Abramo, 2013.

FARIA, José Eduardo. Direitos humanos e globalização econômica: notas para uma discussão. Estudos avançados. São Paulo, v.11, nº 30, p. 43-53, 1997.

FERRAZ JUNIOR, Tércio Sampaio. Introdução ao

Estudo do Direito: técnica, decisão, dominação. $6^{\mathrm{a}}$ ed. São Paulo: Atlas, 2008.
GONÇALVES, Maria Eduarda. Direito da informação: novos direitos e formas de regulação na sociedade da informação. Coimbra: Almedina, 2003.

GRAU, Eros Roberto. A ordem econômica na

Constituição de 1988. São Paulo: RT, 1991.

IANNI, Octavio. Teorias da globalização. Rio de Janeiro: Civilização Brasileira, 2007. A sociedade global. Rio de Janeiro:

Civilização Brasileira, 2008.

LIMA, Venício. Regulação das comunicações: história, poder e direitos. São Paulo: Paulus, 2011.

MATTELART, Armand. A globalização da comunicação. Bauru: Edusc, 2002.

MENDEL, Toby; SALOMON, Eve. Liberdade de expressão e regulação da radiodifusão. UNESCO, Série Debates CI, 2011.

ORTIZ, Renato. Mundialização e cultura. São Paulo: Brasiliense, 2007.

RAMOS, Murilo César. Comunicação, direitos sociais e políticas públicas. In: MARQUES DE MELO, José; SATHLER, Luciano (Org.). Direitos à Comunicação na Sociedade da Informação. São Bernardo do Campo, SP: Umesp, 2005.

REY, Gérman. 0 cenário móvel da televisão pública: alguns elementos. In: RICÓN, Omar (Org.). Televisão pública: do consumidor ao cidadão. São Paulo:

Friedrich-Ebert-Stiftung, 2002. p. 81-118.

THOMPSON, John. A mídia e a modernidade: uma teoria social da mídia. Petrópolis: Vozes, 2008. 


\section{Transnational dynamic of media: processes of regulation in the globalization of communication}

\section{Abstract}

This paper aims to identify the laws of Brazil that limit the entrance of international media content in the country and the foreign investment in national media. In the globalization context, the media are characterized by their transnational dynamic as well as by the formation of global conglomerates that dominate production and distribution of symbolic goods. Thus, this exploratory research shows that Brazilian legislation relies on rules in order to guarantee visibility of local, regional, and national content in front of the global, asymmetrical, and concentrated expansion of media industry. This study comprehends that communication policies exclusively conceived in a national dimension do not adequately address the globalization of communication scenario.

\section{Keywords}

Media. Globalization. Pluralism. Regulation.

\section{Dinámica transnacional de los medios: procesos de regulación} en la globalización comunicacional

\section{Resumen}

Este artículo tiene como objetivo identificar los límites impuestos por las leyes de Brasil en relación con el contenido de los medios internacionales que llegan al país y con la inversión extranjera en los medios de comunicación nacionales. En un contexto marcado por la globalización, los medios de comunicación se caracterizan por su dinámica transnacional y por la formación de conglomerados globales que dominan la producción y distribución de bienes simbólicos. Delante de ese panorama, esta investigación demuestra que la legislación brasileña posee medidas que buscan asegurar espacios para los contenidos local, regional y nacional delante de la expansión global, asimétrica y concentrada de la industria de los medios. Se puede concluir de este estudio que las políticas de comunicación concebidas exclusivamente a escala nacional no contemplan adecuadamente el escenario presentado por los medios globalizados.

\section{Palabras clave}

Medios. Globalización. Pluralidad. Regulamentación. 


\section{Expediente}

A revista E-Compós é a publicação científica em formato eletrônico da Associação Nacional dos Programas de Pós-Graduação em Comunicação (Compós). Lançada em 2004, tem como principal finalidade difundir a produção acadêmica de pesquisadores da área de Comunicação, inseridos em instituições do Brasil e do exterior.

\section{E-COMPÓS I www.e-compos.org.br I E-ISSN 1808-2599}

Revista da Associação Nacional dos Programas de Pós-Graduação em Comunicação. Brasília, v.19, n.2, maio/ago. 2016. A identificação das edições, a partir de 2008, passa a ser volume anual com três números. Indexada por Latindex I www.latindex.unam.mx

\section{CONSELHO EDITORIAL}

\section{Alexandre Farbiarz, Universidade Federal Fluminense, Brasi}

Alexandre Rocha da Silva, Universidade Federal do Rio Grande do Sul, Brasil Ana Carolina Escosteguy, Pontifícia Universidade Católica do Rio Grande do Sul, Brasil Ana Carolina Rocha Pessôa Temer, Universidade Federal de Goiás, Brasil Ana Regina Barros Rego Leal, Universidade Federal do Piauí, Brasil Andrea França, Pontifícia Universidade Católica do Rio de Janeiro, Brasil André Luiz Martins Lemos, Universidade Federal da Bahia, Brasil Antonio Carlos Hohlfeldt, Pontifícia Universidade Católica do Rio Grande do Sul, Brasil Arthur Ituassu, Pontifícia Universidade Católica do Rio de Janeiro, Brasil Álvaro Larangeira, Universidade Tuiuti do Paraná, Brasil

Ângela Freire Prysthon, Universidade Federal de Pernambuco, Brasil César Geraldo Guimarães, Universidade Federal de Minas Gerais, Brasil Cláudio Novaes Pinto Coelho, Faculdade Cásper Líbero, Brasil Daisi Irmgard Vogel, Universidade Federal de Santa Catarina, Brasil Denize Correa Araujo, Universidade Tuiuti do Paraná, Brasil Eduardo Antonio de Jesus, Pontifícia Universidade Católica de Minas Gerais, Brasil Daniela Zanetti, Universidade Federal do Espírito Santo, Brasil Eduardo Vicente, Universidade de São Paulo, Brasil

Elizabeth Moraes Gonçalves, Universidade Metodista de São Paulo, Brasil Erick Felinto de Oliveira, Universidade do Estado do Rio de Janeiro, Brasil Francisco Elinaldo Teixeira, Universidade Estadual de Campinas, Brasil Francisco Paulo Jamil Almeida Marques, Universidade Federal do Paraná, Brasil Gabriela Reinaldo, Universidade Federal do Ceará, Brasil

Goiamérico Felício Carneiro Santos, Universidade Federal de Goiás, Brasil Gustavo Daudt Fischer, Universidade do Vale do Rio dos Sinos, Brasil Herom Vargas, Universidade Municipal de São Caetano do Sul, Brasil Itania Maria Mota Gomes, Universidade Federal da Bahia, Brasil Janice Caiafa, Universidade Federal do Rio de Janeiro, Brasil Jiani Adriana Bonin, Universidade do Vale do Rio dos Sinos, Brasil
José Afonso da Silva Junior, Universidade Federal de Pernambuco, Brasil José Luiz Aidar Prado, Pontifícia Universidade Católica de São Paulo, Brasil Juçara Gorski Brittes, Universidade Federal de Ouro Preto, Brasil Kati Caetano, Universidade Tuiuti do Paraná, Brasil Lilian Cristina Monteiro França, Universidade Federal de Sergipe, Brasil Liziane Soares Guazina, Universidade de Brasilia, Brasil Luíza Mônica Assis da Silva, Universidade de Caxias do Sul, Brasil Luciana Miranda Costa, Universidade Federal do Pará, Brasil Malena Segura Contrera, Universidade Paulista, Brasil Monica Martinez, Universidade de Sorocaba, Brasil Maria Ataide Malcher, Universidade Federal do Pará, Brasil Marcia Tondato, Escola Superior de Propaganda e Marketing, Brasil Marcel Vieira Barreto Silva, Universidade Federal da Paraiba, Brasil Maria Clotilde Perez Rodrigues, Universidade de São Paulo, Brasil Maria das Graças Pinto Coelho, Universidade Federal do Rio Grande do Norte, Brasil Mauricio Ribeiro da Silva, Universidade Paulista, Brasil

Mauro de Souza Ventura, Universidade Estadual Paulista, Brasil Márcio Souza Gonçalves, Universidade do Estado do Rio de Janeiro, Brasil Micael Maiolino Herschmann, Universidade Federal do Rio de Janeiro, Brasil Mirna Feitoza Pereira, Universidade Federal do Amazonas, Brasil Nísia Martins Rosario, Universidade Federal do Rio Grande do Sul, Brasil Potiguara Mendes Silveira Jr, Universidade Federal de Juiz de Fora, Brasil Regiane Regina Ribeiro, Universidade Federal do Paraná, Brasil Rogério Ferraraz, Universidade Anhembi Morumbi, Brasil Rose Melo Rocha, Escola Superior de Propaganda e Marketing, Brasil Rozinaldo Antonio Miani, Universidade Estadual de Londrina, Brasil Sérgio Luiz Gadini, Universidade Estadual de Ponta Grossa, Brasil Simone Maria Andrade Pereira de Sá, Universidade Federal Fluminense, Brasil Veneza Mayora Ronsini, Universidade Federal de Santa Maria, Brasil Walmir Albuquerque Barbosa, Universidade Federal do Amazonas, Brasil
COMISSÃO EDITORIAL Eduardo Antonio de Jesus, Pontifícia Universidade Católica de Minas Gerais, Brasil I Osmar Gonçalves dos Reis Filho, Universidade Federal do Ceará, Brasi

CONSULTORES AD HOC Alexandre Almeida Barbalho, Universidade Estadual do Ceará, Brasil | Alexandre Rocha da Silva, Universidade Federal do Rio Grande do Sul, Brasil | Bruno Souza Leal, Universidade Federal de Minas Gerais, Brasil I Carlos Eduardo Franciscato, Universidade Federal do Sergipe, Brasil I Eneus T. Barreto Filho, Universidade de São Paulo, Brasil I Felipe da Costa Trotta, Universidade Federal Fluminense, Brasi | Henrique Codato, Universidade Federal do Ceará, Brasil I Ines S. Vitorino Sampaio Universidade Federal do Ceará, Brasil I Jairo Getulio Ferreira, Universidade do Vale do Rio dos Sinos, Brasil I Juliana Freire Gutmann, Universidade Federal da Bahia, Brasil | Júlio César M. Pinto, Pontifícia Universidade Católica de Minas Gerais, Brasil I Lucrecia D. Ferrara, Pontifícia Universidade Católica de São Paulo, Brasil I Marcio V. Serelle, Pontifícia Universidade Católica de Minas Gerais, Brasil I Maria Ignes C. Magno, Universidade Anhemb Morumbi, Brasil I Maria Lilia Dias de Castro, Universidade Federal de Santa Maria, Brasil | Mozahir S. Bruck, Pontifícia Universidade Católica de Minas Gerais, Brasil I Potiguara M. da Silveira Junior, Universidade Federal de Juiz de Fora, Brasil I Sandra Maria L. P. Gonçalves, Universidade Federal do Rio Grande do Sul, Brasil I Suzana Kilpp, Universidade do Vale do Rio dos Sinos, Brasil I Tiago Q. Fausto Neto, Universidade de Brasília, Brasil I Vera Regina V. Franca, Universidade Federal de Minas Gerais, Brasil I Virginia P. S. Fonseca, Universidade Federal do Rio Grande do Sul, Brasil

EQUIPE TÉCNICA ASSISTENTE EDITORIAL Márcio Zanetti Negrini REVISÃo DE TEXTOS Press Revisão I EDITORAÇÃO ELETRÔNICA Roka Estúdio

\section{COMPÓS I www.compos.org.br}

Associação Nacional dos Programas de Pós-Graduação em Comunicação

Presidente

Edson Fernando Dalmonte

Programa de Pós-Graduação em Comunicação

e Cultura Contemporânea - UFBA

edsondalmonte@uol.com.br

Vice-presidente

Cristiane Freitas Gutfreind

Programa de Pós-Graduação em Comunicação Social - PUC-RS cristianefreitas@pucrs.br

Secretário-Geral

Rogério Ferraraz

Programa de Pós-Graduação em Comunicação

Universidade Anhembi Morumbi

rogerioferraraz@anhembimorumbi.edu.br

CONTATO I revistaecompos@gmail.com 